\title{
Onset and offset of aversive events establish distinct memories requiring fear and reward networks
}

\author{
Marta Andreatta, ${ }^{1,6}$ Markus Fendt, ${ }^{2,6,7}$ Andreas Mühlberger, ${ }^{1}$ Matthias J. Wieser, ${ }^{1}$ \\ Stefan Imobersteg, ${ }^{2}$ Ayse Yarali, ${ }^{3}$ Bertram Gerber, ${ }^{4,5}$ and Paul Pauli ${ }^{1,7}$ \\ ${ }^{1}$ Department of Psychology, Julius Maximilians University, 97070 Würzburg, Germany; ${ }^{2}$ Neuropsychiatry, Novartis Institutes for \\ BioMedical Research, 4056 Basel, Switzerland; ${ }^{3}$ Max Planck Institute of Neurobiology, 82152 Martinsried, Germany; ${ }^{4}$ Leibniz Institute \\ of Neurobiology (LIN), Department of Genetics of Learning and Memory, 39104 Magdeburg, Germany; Institute of Biology, \\ Department of Behavioural Genetics, Otto von Guericke University, 39104 Magdeburg, Germany
}

\begin{abstract}
Two things are worth remembering about an aversive event: What made it happen? What made it cease? If a stimulus precedes an aversive event, it becomes a signal for threat and will later elicit behavior indicating conditioned fear. However, if the stimulus is presented upon cessation of the aversive event, it elicits behavior indicating conditioned "relief." What are the neuronal bases for such learning? Using functional magnetic resonance imaging (fMRI) in humans we found that a fearconditioned stimulus activates amygdala but not striatum, whereas a relief-conditioned stimulus activates striatum but not amygdala. Correspondingly, acute inactivation of amygdala or of ventral striatum in rats respectively abolished only conditioned fear or only conditioned relief. Thus, the behaviorally opponent memories supported by onset and offset of aversive events engage and require fear and reward networks, respectively. This may explain attraction to stimuli associated with the cessation of trauma or of panic attacks.
\end{abstract}

[Supplemental material is available for this article.]

We avoid pain and seek reward. To this end, stimuli can become associated with these respective salient events (Pavlov 1927). For example, if a visual stimulus is repeatedly followed by an electric shock, it will be learned as a threat and will elicit conditioned fear. A behavioral indicator of such conditioned fear in humans and other mammals is increased "jumpiness" measured as an increased startle response in the presence of the learned stimulus (Davis et al. 1993; Fendt and Fanselow 1999; Grillon and Baas 2003). The neuronal basis of such conditioned fear and the crucial involvement of the amygdala is well examined in humans and rodents (Davis et al. 1993; Lavond and Kim 1993; Davis 1994; Büchel et al. 1998; LaBar et al. 1998; Fendt and Fanselow 1999; LeDoux 2000; Ashburner and Friston 2003; Hamm and Weike 2005; Tabbert et al. 2006). Importantly, timing matters for such learning: Reflecting the predictive nature of the association process, learning is best if the stimulus shortly precedes the shock (e.g., Burman and Gerwitz 2004); this appears to be one of the few universals across associative learning preparations (Rescorla 1988).

However, what happens if the sequence of events during training is reversed, i.e., if the to-be-conditioned stimulus is presented after the shock? In Drosophila, such training establishes conditioned approach to the stimulus (Tanimoto et al. 2004; Yarali et al. 2008), indicating that it has been learned as a signal for "relief" from shock (Solomon 1980; Wagner 1981) or for "respite" (Lohr et al. 2007) or "safety" (Sutton and Barto 1990; Chang et al. 2003; Leknes et al. 2011) related to the shock-free

\footnotetext{
${ }^{6}$ These authors contributed equally to this work.

${ }^{7}$ Corresponding authors

E-mail markus.fendt@web.de

E-mail pauli@mail.uni-wuerzburg.de

Article is online at http://www.learnmem.org/cgi/doi/10.1101//m.026864.112.

Freely available online through the Learning \& Memory Open Access option.
}

safe period within the shock-associated dangerous experimental context. The relief-based explanation appears more fitting in this case, because "safety conditioning" should rely on the strength of the context-shock association (e.g., Chang et al. 2003) and on the length of the shock-free safe period following the stimulus (e.g., Moscovitch and LoLordo 1968), but neither of these seems to be the case in Drosophila (Yarali et al. 2008).

Paralleling the situation in Drosophila, training humans with first shock and then the conditioned stimulus leads to a decrease in the amplitude of the startle response in the presence of this stimulus, in contrast to the increase in startle amplitude observed after fear conditioning (Andreatta et al. 2010). Thus, one and the same shock episode presumably leaves two kinds of memory with opponent implicit valences indicated by startle potentiation and startle attenuation: conditioned fear and conditioned relief, respectively. Interestingly, humans explicitly report a negative valence in both cases, despite the opponency of the implicit valences (Andreatta et al. 2010). Notably, this human paradigm, similar to the fly paradigm (Tanimoto et al. 2004; Yarali et al. 2008), enables assaying conditioned fear and conditioned relief directly and within the same behavioral setting. We reasoned that conditioned relief crucially depends on striatal networks, on the one hand because lesion studies in animals revealed that the attenuation of startle responses due to positively valenced events depends on striatal circuits (Koch et al. 1996), and on the other hand because human fMRI studies found evidence that the reduction (Seymour et al. 2005), the omission (Leknes et al. 2011), or the termination (Becerra and Borsook 2008) of an expected painful stimulation is associated with activity in the ventral striatum.

From an applied perspective, these opponent learning processes may bear upon our understanding of behavior in the aftermath of traumatic experiences: Stimuli associated with trauma 
onset will become aversive and motivate avoidance, while stimuli associated with the cessation of trauma and/or the period of safety thereafter should become attractive and motivate approach (Lohr et al. 2007). Also, an imbalance in the processing of danger and relief or safety signals may underlie pathological behavior (Lissek et al. 2005). Therefore, understanding the neuronal mechanisms of the respective learning processes appears warranted.

Here we examine the neuronal mechanisms of fear vs. relief conditioning using fMRI in humans and the effects of local, transient brain inactivation on the startle response in rats. First we ask in humans whether BOLD signals to fear- or relief-conditioned stimuli are seen in the two structures of interest, the amygdala and the striatum, respectively. Second, we examine in rats whether the potentiation or attenuation of the startle response due to fear- or relief-conditioned stimuli respectively depend on intact amygdala or striatum. Particularly, we expect a dissociation confirming the evolutionarily conserved requirement of the amygdala in conditioned fear (Davis et al. 1993; Lavond and Kim 1993; Davis 1994; Büchel et al. 1998; LaBar et al. 1998; Fendt and Fanselow 1999; LeDoux 2000; Hamm and Weike 2005; Tabbert et al. 2006), and here test for the first time for the requirement of striatal circuits for conditioned relief.

\section{Results}

\section{Neural correlates of conditioned fear and conditioned relief in humans}

Human subjects underwent either fear or relief conditioning (Fig. 1A) such that a visual CS was presented either before a mildly painful electric shock $\left(\mathrm{CS}^{\mathrm{SHOCK}}\right)$ or after the shock $\left({ }^{\mathrm{SHOCK}} \mathrm{CS}\right)$. Then, event-related fMRI registered during the following test phase was analyzed for activations by $\mathrm{CS}^{\mathrm{SHOCK}}$ and ${ }^{\mathrm{SHOCK}} \mathrm{CS}$ as compared to a CS that had been presented without shock during training $\left(\mathrm{CS}^{\mathrm{CONTROL}}\right)$ or to a CS that had not been presented during training at all $\left(\mathrm{CS}^{\text {NOVEL}}\right)$. As we (Andreatta et al. 2010) have previously found that $\mathrm{CS}^{\mathrm{SHOCK}}$ potentiates startle (indicating implicit negative valence), whereas ${ }^{\text {SHOCK }}$ CS attenuates startle (indicating implicit positive valence), we hypothesized that fear and/or reward networks may be activated by these stimuli, respectively, and we therefore examined the activity in amygdala and striatum as regions of interest (ROIs).

Fear and relief conditioning caused selective activations within the ROIs (Fig. 2; Table 1). Specifically, after fear conditioning $\mathrm{CS}^{\text {SHOCK }}$ activated the right amygdala more strongly compared with both $\mathrm{CS}^{\text {CONTROL }}(P=0.015$, FWE corrected $)$ and $\mathrm{CS}^{\text {NOVEL }}$ $(P=0.016$, FWE corrected), whereas after relief conditioning ${ }^{\text {SHOCK }} \mathrm{CS}$ activated the right striatum more strongly compared with $\mathrm{CS}^{\mathrm{CONTROL}}$ (putamen, $P=0.013$, FWE corrected). Furthermore, with a lower statistical threshold $(P=0.001$, uncorrected), we were able to confirm that the observed cluster of striatal activation extended into the ventral part of the putamen (Fig. 2B), as defined by the MNI coordinates $(18,8,0)$ given by Seymour et al. (2005), and that the right striatal activation by the ${ }^{\mathrm{SHOCK}} \mathrm{CS}$ was enhanced also relative to the $C S^{\text {NOVEL }}$ (putamen, $P<0.001$, uncorrected). We also observed activation of the left insula (Fig. 2) by both $\mathrm{CS}^{\text {SHOCK }}(P<$ 0.001 , uncorrected) and ${ }^{\text {SHOCK}} \mathrm{CS}(P<0.001$, uncorrected $)$ when compared with CS ${ }^{\text {CONTROL }}$. Notably, we did not find any activation in the amygdala, the striatum, or the insula in response to CS $S^{\text {CONTROL }}$ compared with CS ${ }^{\text {NOVEL }}$.

Analysis of ratings of contingency awareness confirmed that both the fear and the relief conditioning groups discerned the contingencies in the same way (Supplemental Fig. 1). That is, both groups were able to correctly report the association between the visual stimulus and the painful electric shock independent of their relative timing during training (for statistical details see Supplemental Material). Analysis of valence ratings revealed that subjects considered both $\mathrm{CS}^{\mathrm{SHOCK}}$ and ${ }^{\mathrm{SHOCK}} \mathrm{CS}$ equally more negative than the $\mathrm{CS}^{\mathrm{CONTROL}}$ and $\mathrm{CS}^{\mathrm{NOVEL}}$ after conditioning. That is, both fear and relief conditioning, despite the implicit opponency, resulted in explicitly aversive memories (see Supplemental Fig. 2; for statistical details, see Supplemental Material).

\section{Neural requirements of conditioned fear and conditioned relief in rats}

On the basis of the established rat fear-conditioning paradigm, we first established a relief-conditioning paradigm. During learning, we used several positive and negative ISIs between a light CS and shock presentation. Both, using random ISIs as well as only-CS presentations during learning, were considered to be control conditions leading to no CS-related association, allowing us to measure a baseline of startle magnitude in the presence of a "neutral" CS. An overall analysis revealed significant effects of the different ISIs in the learning phase (Kruskal-Wallis test: $H=$ 68.46, $P<0.001$ ). As depicted in Figure $3 \mathrm{~A}$, we observed a weak, nonsignificant attenuation of the startle magnitude by the light cue in the two control conditions (Wilcoxon Signed Rank test;

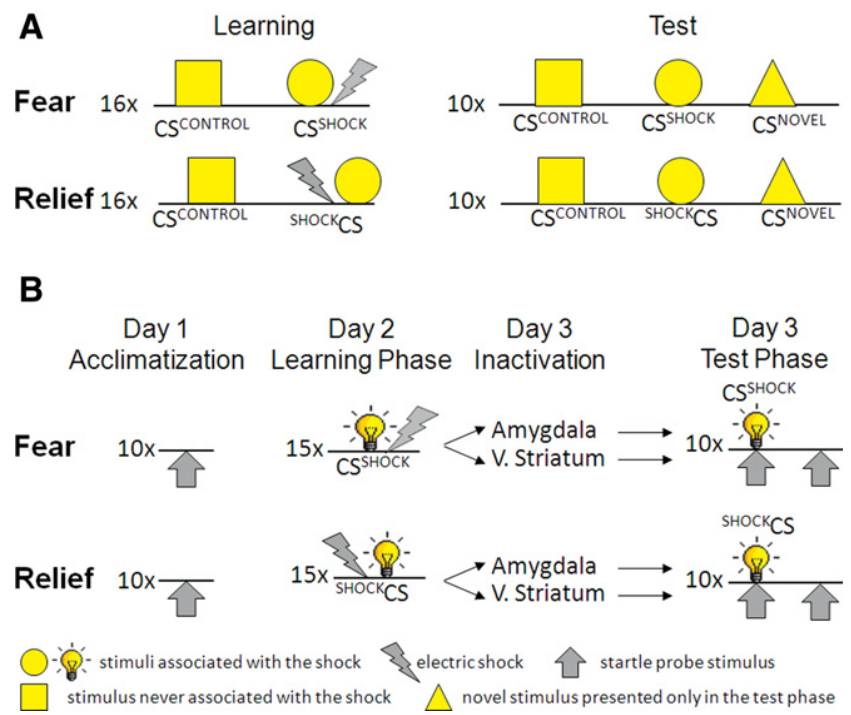

Figure 1. Experimental design. ( $A$ ) Human imaging experiment. Participants either underwent fear conditioning, in which a geometrical shape ( $C S^{\text {SHOCK }}$, e.g., circle) was presented before the shock and thus was to be associated with shock-onset, or relief conditioning, in which a shape $\left({ }^{\text {HOCK }} \mathrm{CS}\right)$ was presented after the shock, to be associated with shock-offset; such training endows the $\mathrm{CS}^{\text {SHOCK }}$ and the ${ }^{\text {SHOCK }} \mathrm{CS}$ with the capacity to respectively potentiate or attenuate startle in humans (Andreatta et al. 2010). In both cases, another shape (CS ${ }^{\text {CONTROL }}$, e.g., square) was presented alone, thus not to be associated with shock. In the test, functional magnetic resonance imaging (fMRI) was used to monitor brain activity in response to $C^{\text {SHOCK }}$ and $C S^{\text {CONTROL }}$ in the case of fear conditioning and to ${ }^{\text {SHOCK }} \mathrm{CS}$ and $\mathrm{CS}^{\mathrm{CONTROL}}$ in the case of relief conditioning. Additionally, a third shape (CS ${ }^{\text {NOVEL }}$, e.g., a triangle), which had never been presented before, was displayed and fMRI activations recorded. (B) Rat lesion experiments. Day 1: All rats were acclimatized to the startle apparatus for $5 \mathrm{~min}$ by delivering 10 startle probe stimuli (i.e., loud noise) at intervals of 30 sec. Day 2: Either the rats underwent fear conditioning, in which a 5-sec light ( $\mathrm{CS}^{\text {SHOCK}}$ ) was associated with shock-onset, or they underwent relief conditioning, in which the light $\left({ }^{\text {SHOCK }} \mathrm{CS}\right)$ was presented after shock-offset. Day 3: Test for conditioned fear or conditioned relief: Startle probe stimuli were delivered in either the presence or absence of the light CS, with the indicated inactivation regimen applied. 


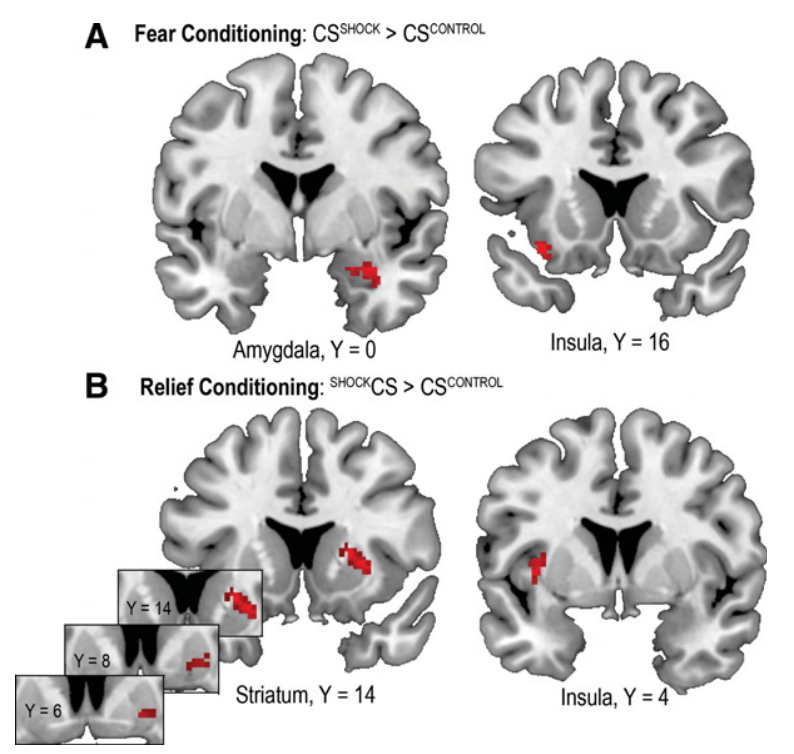

Figure 2. Specific brain activations after fear and relief conditioning. (A) A fear-conditioned visual stimulus, $\mathrm{CS}^{\text {SHOCK}}$, associated with the onset of a mildly aversive electric shock, induced strong activation of the right amygdala (MNI coordinates; peak voxel: $-32,0,-20, Z=3.53, P=0.015$ ), but not of the striatum. (B) A relief-conditioned visual stimulus, ${ }_{\text {SHOCK }}$ CS, associated with the offset of a mildly aversive electric shock, induced strong activation of the right striatum (MNI coordinates, peak voxel: $28,14,2$ [putamen], $Z=4.09, P=0.013$ ), but not of the amygdala; striatum activation extended to the ventral striatum (ventral part of the putamen; coordinates $18,8,0) .(A, B)$ Both $C S^{\text {SHOCK }}$ and ${ }^{{ }^{S H O C K}} C S$ triggered left insula activity (peak voxel: $-36,4,4, Z=3.62, P<0.001$ ) Displayed are BOLD responses triggered by $\mathrm{CS}^{\mathrm{S} H O C K}$ or ${ }^{\mathrm{SHOCK}^{\prime}} \mathrm{CS}$ minus responses triggered by a stimulus not associated with the shock (CS $\left.{ }^{\text {CONTROL }}\right)$. For display, the threshold for activation was set at $P<$ 0.005 (uncorrected).

comparison with zero: only CS, $P=0.08$; rnd, $P=0.57$ ), which were pooled for further analyses (stippled line in Fig. 3A). Post-hoc pairwise comparisons with this pooled control group revealed a significant attenuation of the startle magnitude after relief conditioning (ISI: $-3 \mathrm{sec}$; Dunn's test: $P<0.01$ ). After "normal" fear conditioning (ISI: $+4.5 \mathrm{sec}$ ), on the other hand, the CS, as expected, potentiated startle $(P<0.01)$. Yet longer positive ( $\geq 12 \mathrm{sec}$ ) or negative ( $\geq 6 \mathrm{sec}$ ) ISIs were without significant effect on startle magnitude. Accordingly, for the next experiment, we chose the ISIs of $+4.5 \mathrm{sec}$ for fear conditioning and $-3 \mathrm{sec}$ for

Table 1. Coordinates and statistics for the human imaging study

\begin{tabular}{|c|c|c|c|c|c|c|}
\hline & ROI & $x$ & $y$ & $z$ & $Z$-value & $P$-value \\
\hline \multicolumn{7}{|l|}{ Fear conditioning group } \\
\hline $\begin{array}{l}C S^{\text {SHOCK }} \text { vs. CS } \\
C S^{\text {CONTROL }} \\
\text { SHOCK } v S . C S^{\text {NOVEL }}\end{array}$ & $\begin{array}{l}\text { Right amygdala } \\
\text { Left insula } \\
\text { Right amygdala }\end{array}$ & $\begin{array}{r}32 \\
-34 \\
32\end{array}$ & $\begin{array}{r}0 \\
16 \\
0\end{array}$ & $\begin{array}{l}-20 \\
-16 \\
-30\end{array}$ & $\begin{array}{l}3.53 \\
3.35 \\
3.49\end{array}$ & $\begin{array}{l}0.015^{\mathrm{a}} \\
0.001^{\mathrm{b}} \\
0.016^{\mathrm{a}}\end{array}$ \\
\hline \multicolumn{7}{|l|}{ Relief conditioning group } \\
\hline $\begin{array}{l}{ }^{\text {SHOCK }} \text { CS vS. CS }{ }^{\text {CONTROL }} \\
{ }^{\text {SHOCK}} \text { CS vs. CS NOVEL }\end{array}$ & $\begin{array}{l}\text { Right striatum } \\
\text { Left insula } \\
\text { Right striatum }\end{array}$ & $\begin{array}{r}28 \\
-36 \\
24\end{array}$ & $\begin{array}{r}14 \\
4 \\
14\end{array}$ & $\begin{array}{l}2 \\
4 \\
4\end{array}$ & $\begin{array}{l}4.09 \\
3.62 \\
3.70\end{array}$ & $\begin{array}{l}0.013^{\mathrm{a}} \\
0.001^{\mathrm{b}} \\
0.001^{\mathrm{b}}\end{array}$ \\
\hline
\end{tabular}

${ }^{\mathrm{a} F W E}$ corrected

buncorrected

The coordinates of the voxels refer to the Montreal Neurological Institute (MNI). Notably, no significant activation has been found to the reverse contrasts: $\mathrm{CS}^{\mathrm{CONTROL}}$ vs. $\mathrm{CS}^{\text {SHOCK }}, \mathrm{CS}^{\mathrm{CONTROL}}$ vs. ${ }^{\text {SHOCK}}{ }^{\mathrm{CS}}$, and CS ${ }^{\text {CONTROL }}$ vS. ${ }^{\text {NOVEL }}$ CS. relief conditioning. These ISIs induced robust and stable startle potentiation and attenuation, respectively (Fig. 3B,C).

To test whether the amygdala or the ventral striatum (i.e., nucleus accumbens) is required for the expression of fear or relief conditioning, we acutely inactivated these areas by local injections of muscimol after the respective training, before the retrieval test (Fig. 1B; for injection sites see Supplemental Fig. 3). Muscimol is a GABA-A receptor agonist and leads to a local and transient inhibition of neural activity (Martin 1991). We found that the muscimol effect on fear conditioning depended on the injection site (Fig. 4) (ANOVA, Site $\times$ Treatment: $F_{(1,13)}=7.78, \quad P=0.02$ ). Fear-potentiated startle was blocked by acute inactivation of the basolateral amygdala (post-hoc comparison vehicle vs. muscimol: $t=3.19, P=0.02$ ) but not by inactivation of the ventral striatum $(t=-0.93, P=0.39)$. Notably, after relief conditioning (Fig. 4), the effect of muscimol also depended on injection site (ANOVA, Site $\times$ Treatment: $\left.F_{(1,16)}=4.93, P=0.04\right)$. In this case, however, muscimol injections into the amygdala were benign $(t=-0.90$, $P=0.40$ ), whereas acute inactivation of the ventral striatum abolished startle attenuation by the ${ }^{\text {SHOCK}} \mathrm{CS}(t=-3.71, P=0.006)$.

\section{Discussion}

We studied the mnemonic effects of shock-onset and shock-offset using comparable conditioning paradigms in rats and humans. Critically, these paradigms allow assaying opponently valenced memories formed by the conditioned stimuli directly, namely, by assessing the bidirectional modulation in response to these stimuli (e.g., increasing or decreasing startle amplitude) rather than by indirect tests (e.g., retardation of acquisition, summation). Using such an assay, we demonstrated by fMRI in humans that stimuli associated with the onset or the offset of the same shock episode, respectively, entail activations of the amygdala, which is crucially involved in fear learning and fear expression (Phelps and LeDoux 2005), or of the striatum, which is particularly involved in processing of rewarding events (Delgado and Dickerson 2012). Then, using rats, we asked whether the respective brain areas are also required for the expression of the corresponding conditioned behaviors. To do so, we first supplemented the existing rat fear-conditioning paradigms (Davis et al. 1993; Fendt and Fanselow 1999) with a relief-conditioning protocol. Then we showed that temporary inactivation of the amygdala and the striatum selectively interfere with conditioned fear and conditioned relief, respectively.

Thus, both in human and in rat the associative processes related to the onset and the offset of an aversive event are mediated by different neural substrates. The offset of shock supports conditioned relief, which shares a neuronal signature with conditioned reward (Robbins and Everitt 1996; Gottfried et al. 2002) in that activation of the striatum is observed (Figs. 2B, 4). The onset of shock, in turn, supports fear conditioning, which shows a complementary neuronal signature in that activation of the amygdala but not the striatum is required (Figs. 2, 4; see also Davis 1994; LaBar et al. 1998; Fendt and Fanselow 1999). Thus, shifting the stimulus presentation by only a few seconds has drastic consequences, both on the behavioral (Andreatta et al. 2010) and on the neuronal level (present study). Stimuli paired with one and the same aversive event can induce memories with qualitatively different behavioral valence, dependent 


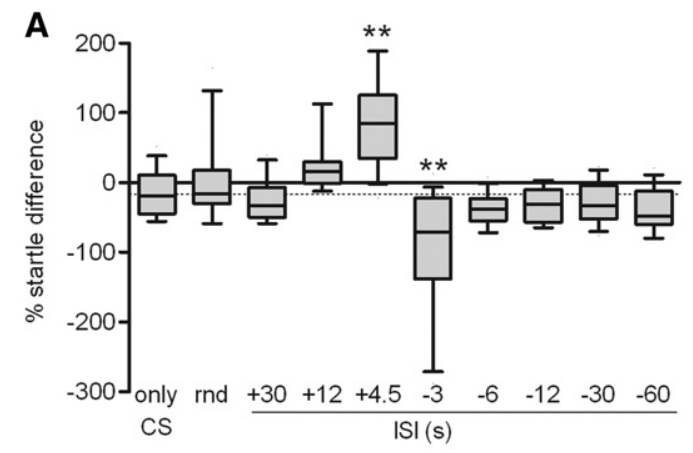

B

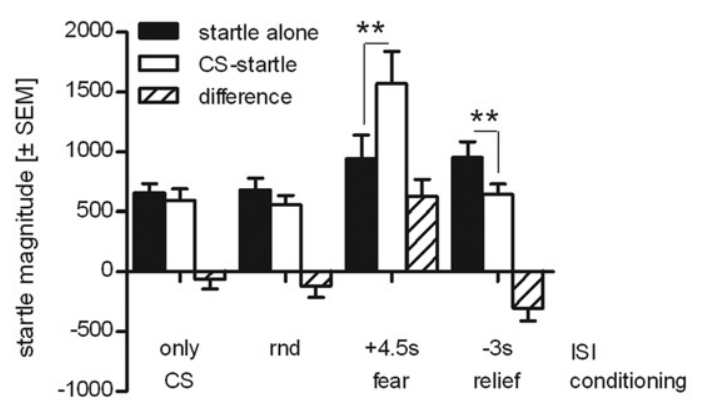

C

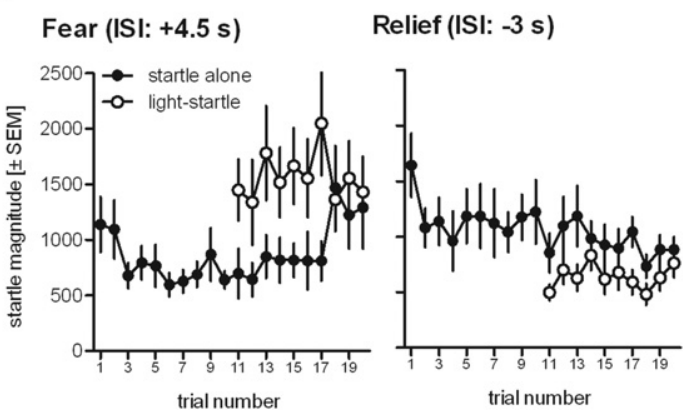

Figure 3. Fear vs. relief conditioning results in potentiation vs. attenuation of startle in rats. During conditioning, 15 pairings of a light stimulus with an electric footshock were presented. Different interstimulus intervals (ISI) were used in the different groups ( $n=12-16 /$ group): positive ISI for fear conditioning and negative ISI for relief conditioning. One day later, the modulating effects of the learned light stimulus on auditory startle was tested. (A) Effects of different ISI. A light stimulus never (CS only) or randomly (rnd) paired with a footshock did not affect the startle magnitude and served as control groups (median after pooling: hatched line). After normal fear conditioning (ISI: $+4.5 \mathrm{sec}$ ), the learned light stimulus significantly potentiated the startle magnitude (displayed are medians, $25 \%$ and $75 \%$ quartiles and $10 \%$ and $90 \%$ quantiles of percent changes of the startle magnitude), whereas after relief conditioning (ISI: $+3 \mathrm{sec}$ ) a significant attenuation of the startle magnitude was observed. ( $\left.{ }^{* *}\right) P<0.01$, Dunn's post-hoc test after main significant effects in a Kruskal-Wallis test. Means $(B)$ and time courses $(C)$ of mean startle magnitude $( \pm$ SEM) in the absence (black bars; filled circles) and the presence of the light (white bars; open circles), as well as the difference (hatched bars) for the groups with ISIs of $+4.5 \mathrm{sec}$ and $-3 \mathrm{sec}$, and the control groups.

on whether they precede or follow the event. In the first case, fear networks are activated and startle amplitude is increased, whereas in the second case, reward networks are activated and startle is decreased.

Negative emotions, both in humans (Büchel et al. 1998; LaBar et al. 1998; Hamm and Weike 2005) and in rodents (Rogan et al.
1997; Herry et al. 2008; Ciocchi et al. 2010), are accompanied by activation of the amygdala. If an initially neutral stimulus coincides with such amygdaloid activation (as is the case in fear conditioning) (Fig. 2A) the sensory pathway to the basolateral amygdala is modified (Rogan et al. 1997; Maren 2000) such that when the stimulus is presented again, the amygdala will be activated. This activation produces symptoms of conditioned fear such as a potentiation of the startle response (Fendt and Fanselow 1999; Phelps and LeDoux 2005; Grillon 2008). Indeed, fear conditioning is attenuated or blocked in human patients with selective amygdala damage (Bechara et al. 1995; Siebert et al. 2003) and in animals with inactivated or lesioned amygdala (Fig. 4; Hitchcock and Davis 1986; Helmstetter and Bellgowan 1994; Muller et al. 1997). Accordingly, we find that amygdala is recruited by and required for conditioned fear (Figs. 2, 4).

As for the emotional state induced by the offset of an aversive event, we find reward-like behavioral effects-that is, conditioned attenuation of startle, both in rats (Figs. 2B, 4) and in humans (Andreatta et al. 2010; for related results in flies, see Tanimoto et al. 2004; Yarali et al. 2008). Importantly, such conditioned relief recruits and depends on the striatum, particularly its ventral part (Figs. 2, 4). Dopaminergic neurons projecting to the ventral striatum are activated by reward (Robbins and Everitt 1996; Schultz et al. 1997; Delgado 2007; Wang and Tsien 2011; Delgado and Dickerson 2012) as well as by the reduction or omission of a painful event (Seymour et al. 2005; Becerra and Borsook 2008; Brischoux et al. 2009; Leknes et al. 2011), suggesting an overlap between reward- and relief-related responses. Stimuli presented during reward-induced striatal excitation acquire positive conditioned valence (Jay 2003), as reflected by attenuation of the startle reflex (Schmidt et al. 1995) or the conditioned activation of the ventral striatum (Gottfried et al. 2002). In rats, activity of the ventral striatum is indeed sufficient (Schwienbacher et al. 2006) and necessary (Koch et al. 1996) for startle attenuation by a positively valenced cue. Together with these previous studies, our findings that conditioned relief activates the ventral striatum (Fig. 2B) and that acute inactivation of the ventral striatum blocks startle attenuation by conditioned relief (Fig. 4) point to shared behavioral and neural signatures between conditioned relief and reward. It should be interesting to see at which stage of processing this isomorphism breaks down, and how the range of effects of relief-

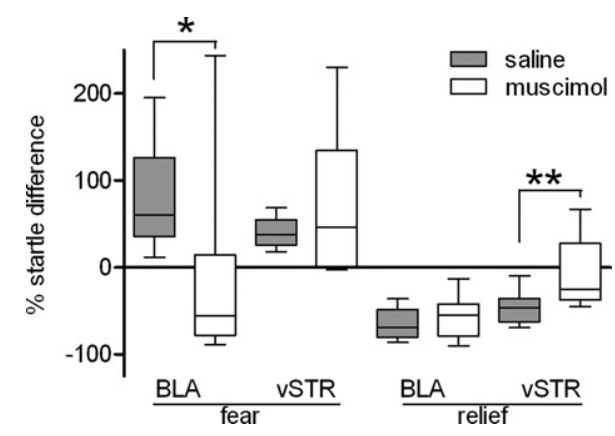

Figure 4. Specific neuronal requirements of conditioned relief and conditioned fear. After training and $\sim 15 \mathrm{~min}$ before probing for the modulation of startle by the learned light stimulus, animals received injections of either saline or muscimol. Muscimol injections lead to a local and transient neural inactivation by activating GABA-A receptors. The effects of fear conditioning were blocked by injections into the basolateral amygdala (BLA, $n=8$ ), but not by injections into the ventral striatum (vSTR; $n=$ 7). In contrast, effects of relief conditioning were reduced by injections into the vSTR $(n=9)$, but not by injections into the BLA $(n=9) .\left({ }^{*}\right) P<$ $\left.0.05,{ }^{* *}\right) P<0.01$, paired $t$-test (Bonferroni corrected) after significant ANOVA effects. 
conditioned stimuli-in particular regarding explicit value judgments in humans (see next section) and safety-seeking and exploration behavior in rodents (Rogan et al. 2005) — compares with the kinds of effect supported by reward-associated stimuli.

It is well established in the literature that the amygdala has a prominent role in fear-related responses, as it is for the dopaminergic projections to the striatum in reward-related responses. However, more recent studies indicate that the amygdala may also be involved in coding rewarding stimuli (Paton et al. 2006; Belova et al. 2007; Murray 2007; Calu et al. 2010) and that the striatum may also be involved in coding aversive events (Jensen et al. 2003; Delgado et al. 2008; Kluchen et al. 2009; Levita et al. 2009; Mechias et al. 2010). On the one hand, the reward-related activation in the amygdala has been circumscribed to only some neurons (Paton et al. 2006; Belova et al. 2007; Murray 2007), suggesting that the amygdala processes rewards and threats in two different ways (LeDoux 2012). More importantly, the amygdala has been implicated in coding the expectation of biologically salient events, either aversive or appetitive (Belova et al. 2007; Li et al. 2011). Therefore, the amygdala activation in response to the $\mathrm{CS}^{\mathrm{SHOCK}}$ in our study suggests that fear-related responses may be due to the expectation of the painful shock. On the other hand, the threat-related activation in the striatum has been circumscribed to the learning phase only, i.e., to the conditioning itself (Jensen et al. 2003; Delgado et al. 2008; Kluchen et al. 2009; Mechias et al. 2010; Li et al. 2011). Since this study examined striatal activation only after conditioning, i.e., during the test phase, we are reluctant to interpret the observed striatum activation as threat-related (Jensen et al. 2003; Kluchen et al. 2009).

Despite the opposing effects of fear and relief conditioning in terms of implicit valence (i.e., startle amplitude modulation, brain activity), humans explicitly judge relief-conditioned stimuli as "emotionally negative" (Andreatta et al. 2010; Supplemental Fig. 2). This rift between explicit and implicit responses supports dual-process theories (e.g., Strack and Deutsch 2004; Bechara and Damasio 2005), which suggest that human behavior is induced by the synergistic or antagonist work of an impulsive system and a reflective system. The former is based on implicit associative processes, the latter on explicit cognitive processes. In this context, we note that both fear- and relief-conditioned stimuli activate the insula (Fig. 2). The insula has been proposed to be a neural substrate for the integration of sensory and cognitive-motivational afferent inputs (Craig 2002, 2009; Mechias et al. 2010). It is thus tempting to speculate that the insula may be involved in the generation of explicit emotional judgments.

Throughout this study, we presented our results within the framework of the opponent-process theory of acquired motivation (Solomon 1980; Wagner 1981), proposing two processes induced by one and the same aversive event: an immediate and negative emotional state triggered by the aversive event's onset and a delayed and positive emotional state triggered by the offset of the aversive event. A possible alternative interpretation would be that the ${ }^{\text {SHOCK }} \mathrm{CS}$ comes to signal a following period of safety until the delivery of the shock in the subsequent training trial (Sutton and Barto 1990; Chang et al. 2003), and such safety conditioning shares neural bases with reward conditioning (Rogan et al. 2005; Leknes et al. 2011). In fact, in the present rat paradigm, the weak startle attenuation after training with long ISIs (Fig. 3A) could be interpreted as such. However, we consider this less likely with respect to the relevant ${ }^{\text {SHOCK }} \mathrm{CS}$ since we find the conditioned modulation of the startle response amplitude to not depend on the duration of such a safety-period in a trivial way (see also Introduction). Rather, at least in the rat, the conditioned relief response was only established using a very short negative ISI (Fig. 3A), arguing for a "relief"-based explanation.
However, we have to admit that we cannot unequivocally conclude that the ${ }^{\mathrm{SHOCK}} \mathrm{CS}$-triggered striatal activity in our human participants is due to an association of the ${ }^{\mathrm{SHOCK}} \mathrm{CS}$ with relief, es-

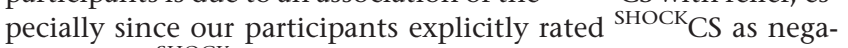
tively as $\mathrm{CS}^{\mathrm{SHOCK}}$ and we did not measure the implicit valence, e.g., by modulation of the startle response. However, we can infer relief, based on our past observation of startle attenuation by the ${ }^{\text {SHOCK }} \mathrm{CS}$ (Andreatta et al. 2010). This previous experiment was not done in an fMRI scanner and thus may not optimally compare with our present experiments; however, we note that the scanner environment likely does not considerably change startle modulation (Anders et al. 2004).

In any case, we think that our results can help to understand some features of odd and/or pathological behavior. For example, "having survived" a roller-coaster ride or extreme sports may support relief conditioning and thus explain the attraction to such dangerous activities (Wang and Tsien 2011). In the same vein, the relief experienced by a hostage following acute repeated death threats may help explain the development of positive behavior toward the hostage taker. Relief conditioning may also contribute to the attraction of anxiety patients to stimuli associated with fear-offset such as medication, the hospital, or therapy environment, and may likewise explain why items not plausibly related to but temporally linked with fear-offset can become "fearfighting" talismans. Similar scenarios may apply regarding the offset of panic attacks and the safety-seeking behavior that may emerge (Himadi 1987; Lohr et al. 2007). Further, hypervigilance to signals of upcoming threats (Bishop 2007) together with a deficit in perception or learning of threat-offset signals may turn a bad experience into a mnemonically unbearable one, and thus contribute to post-traumatic stress (PTSD) or panic disorders (Mineka and Oehlberg 2008; Jovanovic et al. 2010). We noted that, in flies at least, memories after fear conditioning are temporally less stable than memories after relief conditioning (see Fig. 7 in Yarali et al. 2008); if this were the case in humans too, the consequences of degraded relief learning may surface with delay, consistent with the incubation often observed for PTSD symptoms (Bonne et al. 2004). In any event, our results prompt us to consider the role of relief conditioning in the development and maintenance of exaggerated risk taking, excessive safety seeking, posttraumatic stress, and panic disorders, including the question of whether the chosen therapy is differentially effective for fear and relief memories, or not.

\section{Materials and Methods}

\section{Human imaging study}

\section{Participants}

A total of 28 right-handed volunteers (15 female; mean age $=$ $22.68 \mathrm{yr} ; \mathrm{SD}=2.72$; range $=19-29$ ) free of neurological, psychiatric, and chronic pain disorders and acute pain medication gave informed consent and were randomly assigned to the fear $(n=14)$ or the relief $(n=14)$ conditioning group. The study was approved by the ethics committee of the German Society of Psychology (Deutsche Gesellschaft für Psychologie, DGPs).

\section{Stimuli and pre-experimental setup}

The unconditioned aversive stimulus (US) was a 200-msec-long cutaneous electric pulse stimulation at $50 \mathrm{~Hz}$, applied to the left index finger via surface bar electrodes consisting of two durable gold-pasted stainless-steel disk electrodes with $9 \mathrm{~mm}$ diameter, $30 \mathrm{~mm}$ spacing, and an impedance of $5 \Omega$. Stimulation was generated by a constant-current stimulator (Digitimer DS7A) supplying a maximum of $400 \mathrm{~V}$ and $10 \mathrm{~mA}$. The intensity of the US was 
individually adjusted before the experiment with a pain threshold procedure consisting of two series of electrical stimuli of ascending and descending intensities (steps of $0.5 \mathrm{~mA}$ ) (Reiff et al. 1999). Participants evaluated the intensity of each stimulus on a scale ranging from 0 (no pain at all) across 4 (just noticeable pain) to 10 (unbearable pain). The individually adjusted US was defined as the mean of the intensities rated as "just noticeable pain" (i.e., 4) plus $1 \mathrm{~mA}$. Groups did not differ regarding the intensity of the electric shock thus determined $\left(F_{(1,26)}=1.80, P=0.191\right)$.

The conditioned stimuli (CS) were geometric shapes (a square, a circle, and a triangle) of solid yellow color with identical luminance displayed for 10 sec on a black background via MRIcompatible goggles (VisuaStim, Magnetic Resonance Technologies) using the software Presentation 11.1 (Oracle).

\section{Experimental procedure}

Before starting the experiment, participants completed the German version of the State-Trait Anxiety Inventory (Laux et al. 1981) (groups did not differ: $\left.F_{(1,26)}=0.001, P=0.975\right)$ and the pain threshold assessment. Then, in the scanner, participants first underwent an anatomical scan in the absence of any stimulation. The experiment then consisted of two phases: learning and test (see Fig. 1A) following the design of Andreatta et al. (2010).

Both experimental groups completed a differential conditioning procedure, which only differed in the temporal sequence of CS onset and US onset (interstimulus interval; ISI). In the fearconditioning group the $\mathrm{CS}^{\mathrm{SHOCK}}$ started $10 \mathrm{sec}$ before US onset (ISI = $10 \mathrm{sec}$ ), while the CS ${ }^{\mathrm{CONTROL}}$ was not paired with the US. In the relief-conditioning group, the ${ }^{\text {SHOCK }} \mathrm{CS}$ started $6 \mathrm{sec}$ after US onset (ISI $=-6 \mathrm{sec}$ ), while the $\mathrm{CS}^{\mathrm{CONTROL}}$ was not paired with the US. Both groups completed 32 conditioning trials, 16

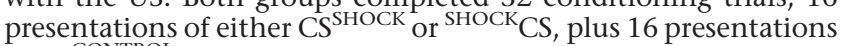
of CS ${ }^{\mathrm{CONTROL}}$. Stimuli were presented in a pseudo-randomized order, that is, the same stimulus was never presented more than twice in a row. The intertrial interval (ITI; i.e., the interval between the offset of the last stimulus of one trial and the onset of the first stimulus of the following trial) was $20 \mathrm{sec}$. After conditioning, all participants went through 30 test trials during which the crucial fMRI measurement took place: 10 trials with either $\mathrm{CS}^{\text {SHOCK }}$ or ${ }^{{ }^{S H O C K}} \mathrm{CS}$ presentation, 10 trials with $\mathrm{CS}^{\mathrm{CONTROL}}$ presentation, and 10 trials with presentations of a novel visual stimulus ( $\left.\mathrm{CS}^{\mathrm{NOVEL}}\right)$ that had not been presented during conditioning.

Before and after the experiment, participants were asked to rate the valence and the arousal of the CSs as well as the contingency between the CSs and the US (see Supplemental Materials for methods and most results).

\section{Magnetic resonance imaging}

Brain images were acquired using a 1.5-T MR scanner (Avanto 1.5T, Siemens) with a standard head coil. The structural-image acquisition consisted of 160 T1-weighted sagittal magnetizationprepared rapid gradient-echo imaging (MP-RAGE) 3D MRI sequences (MPRAGE, 1-mm slice thickness, TR $=2250 \mathrm{msec}, \mathrm{TE}=$ $3.93 \mathrm{msec}, 8^{\circ}$ flip angle, FOV $=250 \mathrm{~mm}$, matrix $=256 \times 256$, voxel size $=1 \times 1 \times 1 \mathrm{~mm}$ ). For functional imaging, a total of 940 volumes for the fear conditioning group and a total of 1004 volumes for the relief conditioning group were registered using a $\mathrm{T}^{*}{ }_{2}$-weighted gradient echo-planar imaging sequence (EPI) with 25 axial slices parallel to the $\mathrm{AC}-\mathrm{PC}$ line and covering the whole brain (5-mm slice thickness; 1-mm gap, descending order, $\mathrm{TA}=100 \mathrm{msec} ; \mathrm{TE}=40 \mathrm{msec}, \mathrm{TR}=2500 \mathrm{msec}$, flip angle $=90^{\circ}$, field of view $=240 \times 240 \mathrm{~mm}$, matrix size $=64 \times 64$, voxel size $=3.1 \times 3.1 \times 5 \mathrm{~mm}$ ).

\section{Data analysis}

fMRI data were analyzed using Statistical Parametric Mapping (SPM5, Wellcome Department of Cognitive Neurology) in MatLab 7.0 (Mathworks, Inc.). Realignment (b-spline interpolation) and slice time corrections were performed (Ashburner and Friston 2003). To allow localization of functional activation on the participants' structural MRIs, T1-scans were coregistered to each participant's mean image of the realigned functional images. Coregistered T1 images were then segmented, and in the next step EPI images were spatially normalized into the Montreal Neurological Institute (MNI) space using the normalization parameters obtained from the segmentation procedure (voxel size $2 \times 2 \times$ $2 \mathrm{~mm}^{3}$ ) and spatially smoothed with an 8-mm full-width halfmaximum (FWHM) Gaussian kernel. The experimental conditions were modeled by convolving stick functions with the canonical hemodynamic response function (HRF). The six movement parameters of the rigid body transformation were introduced as covariates. The voxel-based time series were filtered with a high-pass filter (128-sec time constant). In order to prevent specific processes implicated by extinction, we considered activations in response to the visual stimuli during the early test trials (LaBar et al. 1998), that is, the first five presentations of $\mathrm{CS}^{\text {SHOCK }}$ or ${ }^{{ }^{H O C K}} \mathrm{CS}, \mathrm{CS} S^{\mathrm{CONTROL}}$ and $\mathrm{CS}^{\text {NOVEL }}$. For each participant, $t$-contrasts (fear conditioning group: $\mathrm{CS}^{\mathrm{SHOCK}}>\mathrm{CS} \mathrm{C}^{\mathrm{CONTROL}}, \mathrm{CS}^{\mathrm{SHOCK}}>\mathrm{CS}^{\mathrm{NOVEL}}$; relief conditioning group: ${ }^{\text {SHOCK }} \mathrm{CS}>\mathrm{CS}{ }^{\text {CONTROL }}$, ${ }^{\text {HOCK }} \mathrm{CS}>\mathrm{CS}^{\text {NOVEL }}$ ) were computed. For a priori expected activations, Region of Interest (ROI) analyses were carried out for amygdala, striatum, insula, anterior cingulate cortex (ACC), and orbitofrontal cortex (OFC) on masks from WFU Pickatlas software (Version 2.4, Wake Forest University, School of Medicine), and separately for the two hemispheres. We expected effects, especially in the right hemisphere, since the right amygdala was reported to be particularly and more strongly involved in conditioning involving sensorial aversive stimuli (Phelps et al. 2004; Kluchen et al. 2009; Mechias et al. 2010), while the left amygdala has been proposed to be particularly involved in instructed fear and linked to verbal and abstracted aversive information (Phelps et al. 2004; Mechias et al. 2010).We also performed separated ROI analysis for the left and the right striatum because we particularly expected the right striatum to be involved in the processing of secondary reinforcers (Seymour et al. 2007; Delgado et al. 2008). For all analyses, a minimum cluster size of five voxels was required (Tabbert et al. 2006). The statistical threshold for activation was set at $P<0.05$ (corrected for familywise error, FWE). However, in order to reveal further activations, we set the statistical threshold at $P<0.001$ (uncorrected) for the insula and a detailed striatum analysis (Schiller et al. 2009).

\section{Rat studies}

\section{Animals}

Male Sprague Dawley rats (200-350 g) were housed in groups of four under standard conditions under a 12-h:12-h light:dark cycle (lights on at 7:00); food and water were available ad libitum. All experiments were carried out during the light phase, performed in accordance with international ethical guidelines for the use of animals in experiments, and were approved by the Basel City Cantonal Veterinary Authority.

\section{Apparatus}

A startle system with eight chambers $(35 \mathrm{~cm} \times 35 \mathrm{~cm} \times 38 \mathrm{~cm})$ was used (SR-LAB, San Diego Instruments). Each chamber contained a small animal enclosure made of a transparent horizontal Plexiglas cylinder with a 9-cm inner diameter and a $16-\mathrm{cm}$ inner length. Movements of the animals were detected by motionsensitive transducers mounted underneath the cylinders. For data acquisition the output signal of the transducers was digitized (sampling rate: $1 \mathrm{kHz}$ ) and stored on a computer. Stored responses were expressed in arbitrary units. For conditioning, electric footshocks (US) and light stimuli (CS) were used. The light stimulus (duration: $5 \mathrm{sec}$ ) was presented to the animals with $20 \mathrm{~W}$ bulbs ( $\sim 700$ lux) mounted to the back of the test chambers. Scrambled footshocks were administered by a floor grid (six parallel bars, $10 \mathrm{~mm}$ apart, and $5 \mathrm{~mm}$ diameter) and had an intensity of $0.8 \mathrm{~mA}$ and a duration of $0.5 \mathrm{sec}$. White background noise (50 dB SPL) and the acoustic startle probe ( $40 \mathrm{msec}, 96 \mathrm{~dB}$ SPL white noise) were generated by high-frequency loudspeakers mounted in the center of the ceiling of the test chambers. 


\section{Establishing relief conditioning in rats}

\section{Behavioral procedure}

On the first day (startle baseline), the animals were put into the startle apparatus, and after 5 min acclimatization 10 startle probe stimuli with an intertrial interval of $30 \mathrm{sec}$ were delivered. Then, animals were brought back into their home cages. Animals were then allocated into groups to yield similar mean baseline startle magnitudes.

On the second day (conditioning), the animals were conditioned. After an acclimatization period of $5 \mathrm{~min}, 15$ pairings of a 5-sec light stimulus with an electric-shock stimulus were delivered with a mean intertrial interval of $150 \mathrm{sec}$ (range: 90-210 sec). There were eight different groups with 12-16 animals each; for each group, different interstimulus intervals (onset-onset ISI) between the light stimulus (conditioned stimulus: CS) and the electric footshock (unconditioned stimulus: US) were used: $-60 \mathrm{sec}$, $-30 \mathrm{sec},-12 \mathrm{sec},-6 \mathrm{sec},-3 \mathrm{sec},+4.5 \mathrm{sec},+12 \mathrm{sec}$, and +30 sec. Positive ISIs mean that the light stimulus is presented before the shock, negative ISIs mean that the light stimulus is presented after the shock. Two further groups were exposed to conditions that should not lead to any associations with the CS: In one group ("only CS"), the CS was presented without any US, in the other group ("rnd" = random), random ISIs between CS and US were used. No startle probes were presented during the conditioning session.

On the third day (retention test), the rats were tested for the magnitude of the startle reflex, either in the presence or absence of the learned light stimulus. Animals were put into the startle apparatus, and after $5 \mathrm{~min}$ of accommodation 10 startle stimuli were administered to habituate the startle response. Then 20 further startle stimuli were presented, half of them in the absence and half of them in the presence of the learned light stimulus (in a pseudorandomized order; intertrial interval: $30 \mathrm{sec}$ ). For each animal, we calculated the mean startle magnitude in the absence (Startle alone) and in the presence of the learned light stimulus (CS-startle), as well as the percent difference between these means.

\section{Statistical analyses}

For each group of animals, the mean percent startle difference was calculated. Since the data were not normally distributed, nonparametric tests were used for statistical analysis: Wilcoxon Signed Rank tests for comparison with zero, the Kruskal-Wallis test for comparison across the different groups, and the Dunn's multiple comparison test for post-hoc comparisons.

\section{The effects of temporary inactivation of the amygdala or ventral striatum on conditioned relief and conditioned fear}

\section{Surgery}

Rats were anesthetized with 1\%-3\% isoflurane and placed into a stereotaxic frame. The skull was exposed and stainless-steel guide cannulae $(22 \mathrm{G}$, length: $6.0 \mathrm{~mm}$ ) were bilaterally implanted, aiming at either the basolateral amygdala $(3.3 \mathrm{~mm}$ caudal and $\pm 5.1 \mathrm{~mm}$ lateral from Bregma, $9.0 \mathrm{~mm}$ ventral from skull) or the ventral striatum $(1.2 \mathrm{~mm}$ rostral and $\pm 2.25 \mathrm{~mm}$ lateral from Bregma, $-8.0 \mathrm{~mm}$ ventral from skull). The guide cannulae were fixed to the skull with dental cement and two to three anchoring screws. To prevent post-surgery pain, the analgesic buprenorphin $(0.05 \mathrm{mg} / \mathrm{kg}$, i.p.) was administered twice per day on the first $2 \mathrm{~d}$ following surgery. Behavioral tests started following full recovery (5-6 d after surgery).

\section{Behavioral procedure}

The same behavioral procedures were used as specified above, using an ISI of $-3 \mathrm{sec}$ for relief conditioning and an ISI of $+4.5 \mathrm{sec}$ for fear conditioning (see Fig. 1B). However, immediately before the test on the third day (retention test), the rats were gently restrained by the experimenter and 28G injectors, connected to Hamilton syringes by tubes, were introduced into the guide can- nulae. A total volume of $0.3 \mu \mathrm{L}$ solution with either saline or muscimol $(0.25 \mu \mathrm{g}$, Sigma-Aldrich) was then injected at a flow rate of $0.1 \mu \mathrm{L} / \mathrm{min}$, controlled by a microinfusion pump (CMA100, CMA). The injector was removed after an additional 60 sec. Animals were then put into the startle apparatus, and after 5 min of accommodation 10 startle stimuli were administered to habituate the startle response. Then 20 further startle stimuli were presented, half of them in the absence and half of them in the presence of the learned light stimulus (in a pseudorandomized order; intertrial interval: $30 \mathrm{sec}$ ). For each animal, the mean startle magnitude of the startle trials in the absence (Startle alone) and in the presence of the learned light stimulus (CS-startle), as well as the percent difference between these means were calculated.

On the next day, a reconditioning was performed (i.e., seven pairings of the stimulus and footshock at the groups' respective ISI). Yet $1 \mathrm{~d}$ later, animals received injections and were tested once more in the same manner as on day 3; however, animals that had received saline on day 3 were injected with muscimol this time, and animals that had received muscimol on day 3 were injected with saline.

After the final behavior test, all rats were sacrificed. For the verification of the injection sites, the brains were removed and immersion-fixed with $4 \%$ formaldehyde, 30\% sucrose. Frontal sections $(100 \mu \mathrm{m})$ were cut on a freezing microtome and counterstained with cresyl violet. The injection sites were localized and the extent of tissue lesions due to cannulation was examined under a light microscope. The injection sites were confirmed by comparison with plates taken from a rat brain atlas (Paxinos and Watson 1997). Animals with misplaced injections or lesions or bleedings in the area of the injection were excluded from further analyses ( 12 out of a total of 45 animals).

\section{Statistical analyses}

The mean percent changes in the startle magnitude were calculated for each group. To determine the effects of muscimol injections into the basolateral amygdala and the nucleus accumbens, a multifactorial analysis of variance (ANOVA) was performed for both fear and relief conditioning. Treatment (saline, muscimol) was used as a within-subject factor, whereas brain site (basolateral amygdala, ventral striatum) was used as a between-subject factor. For post-hoc comparisons, paired $t$-tests with Bonferroni corrections were used.

\section{Conflict of Interest}

M.F. and S.I. are employees of Novartis Pharma AG, which is generally interested in developing compounds for the treatment of psychiatric disorders. M.A, A.M., M.J.W., A.Y., B.G., and P.P. declare no competing financial interests.

\section{Acknowledgments}

This work was funded by the Deutsche Forschungsgemeinschaft (DFG-RTG 1253/1, CRC-TR 58, projects B1 and A6, CRC 779 project B11, and a Heisenberg Fellowship [to B.G.]) and received institutional support from the Universities of Würzburg, Leipzig, and Magdeburg, the Novartis AG Basel, the Max Planck Gesellschaft, the Leibniz Institut für Neurobiologie (LIN), and the Wissenschaftsgemeinschaft Gottfried Wilhelm Leibniz (WGL). We thank C. Büchel (University of Hamburg, Germany) for his contributions to data interpretation and analysis, H.C. Pape (University of Münster, Germany) and M. Heisenberg (University of Würzburg, Germany) for discussion and support, and C.E. Gee (Novartis AG, Basel) for helpful comments on the manuscript. We thank A.B.M. Gerdes for her valuable help in collection and analysis of the human fMRI data, the staff of the Research Center for Magnetic-Resonance-Bavaria (MRB e.V.) for technical assistance, M.M. Plichta for support in the analysis, and E. Asan for support in the anatomical localization. 


\section{References}

Anders S, Lotze M, Erb M, Grodd W, Birbaumer N. 2004. Brain activity underlying emotional valence and arousal: A response-related fMRI study. Hum Brain Mapp 23: 200-209.

Andreatta M, Mühlberger A, Yarali A, Gerber B, Pauli P. 2010. A rift between implicit and explicit conditioned valence after pain-relief learning in humans. P Roy Soc B-Biol Sci 277: 2411-2416.

Ashburner J, Friston KJ. 2003. Rigid body registration. In Human brain function (ed. S Zeki, et al.), pp. 635-653. Academic Press, Oxford, UK.

Becerra L, Borsook D. 2008. Signal valence in the nucleus accumbens to pain onset and offset. Eur J Pain 12: 866-869.

Bechara A, Damasio AR. 2005. The somatic marker hypothesis: A neural theory of economic decision. Game Econ Behav 52: 336-372.

Bechara A, Tranel D, Damasio H, Adolphs R, Rockland C, Damasio AR. 1995. Double dissociation of conditioning and declarative knowledge relative to the amygdala and hippocampus in humans. Science 269: $1115-1118$.

Belova MA, Paton JJ, Morrison SE, Salzman CD. 2007. Expectation modulates neural responses to pleasant and aversive stimuli in primate amygdala. Neuron 55: 970-984.

Bishop SJ. 2007. Neurocognitive mechanisms of anxiety: An integrative account. Trends Cogn Sci 11: 307-316.

Bonne O, Grillon C, Vythilingam M, Neumeister A, Charney DS. 2004. Adaptive and maladaptive psychobiological responses to severe psychological stress: Implications for the discovery of novel pharmacotherapy. Neurosci Biobehav R 28: 65-94.

Brischoux F, Chakraborty S, Brierley DI, Ungless MA. 2009. Phasic excitation of dopamine neurons in ventral VTA by noxious stimuli. Proc Natl Acad Sci 106: 4894-4899.

Büchel C, Morris J, Dolan RJ, Friston KJ. 1998. Brain systems mediating aversive conditioning: An event-related fRMI study. Neuron 20: 947-957.

Burman MA, Gerwitz JC. 2004. Timing of fear expression in trace and delay conditioning measured by fear-potentiated startle in rats. Learn Mem 11: $205-212$

Calu DJ, Roesch MR, Haney RZ, Holland PC, Schoenbaum G. 2010. Neural correlates of variations in event processing during learning in central nucleus of amygdala. Neuron 68: 991-1001.

Chang RC, Blaisdell AP, Miller RR. 2003. Backward conditioning: Mediation by the context. J Exp Psychol Anim B 29: 171-183.

Ciocchi S, Herry C, Grenier F, Wolff SBE, Letzkus JJ, Vlachos I, Ehrlich I, Sprengel R, Deisseroth K, Stadler MB, et al. 2010. Encoding of conditioned fear in central amygdala inhibitory circuits. Nature 468: $277-282$.

Craig AD. 2002. How do you feel? Interoception: The sense of the physiological condition of the body. Nat Rev Neurosci 3: 655-666.

Craig AD. 2009. How do you feel-now? The anterior insula and human awareness. Nat Rev Neurosci 10: $59-70$.

Davis M. 1994. The role of the amygdala in emotional learning. In International review of neurobiology (ed. JB Ronald, RA Harris), Vol. 36, pp. 225-266. Academic Press, San Diego, CA.

Davis M, Falls WA, Campeau S, Kim M. 1993. Fear-potentiated startle: A neural and pharmacological analysis. Behav Brain Res 58: 175-198.

Delgado MR. 2007. Reward-related responses in the human striatum. Ann NY Acad Sci 1104: 70-88.

Delgado MR, Dickerson KC. 2012. Reward-related learning via multiple memory systems. Biol Psychiat 72: 134-141.

Delgado MR, Li J, Schiller D, Phelphs EA. 2008. The role of the striatum in aversive learning and aversive prediction errors. Philos $\operatorname{Tr} R$ Soc Lond B Biol Sci 363: 3787-3800.

Fendt M, Fanselow MS. 1999. The neuroanatomical and neurochemical basis of conditioned fear. Neurosci Biobehav R 23: 743-760.

Gottfried JA, O'Doherty J, Dolan RJ. 2002. Appetitive and aversive olfactory learning in humans studied using event-related functional magnetic resonance imaging. J Neurosci 22: 10829-10837.

Grillon C. 2008. Models and mechanisms of anxiety: Evidence from startle studies. Psychopharmacology 199: 421-437.

Grillon C, Baas J. 2003. A review of the modulation of the startle reflex by affective states and its application in psychiatry. Clin Neurophysiol 114: $1557-1579$

Hamm AO, Weike AI. 2005. The neuropsychology of fear learning and fear regulation. Int J Psychophysiol 57: 5-14.

Helmstetter FJ, Bellgowan PS. 1994. Effects of muscimol applied to the basolateral amygdala on acquisition and expression of contextual fear conditioning in rats. Behav Neurosci 108: 1005-1009.

Herry C, Ciocchi S, Senn V, Demmou L, Müller C, Lüthi A. 2008. Switching on and off fear by distinct neuronal circuits. Nature 454: 600-608.

Himadi WG. 1987. Safety signals and agoraphobia. J Anxiety Disord 1: $345-360$
Hitchcock J, Davis M. 1986. Lesions of the amygdala, but not of the cerebellum or red nucleus, block conditioned fear as measured with the potentiated startle paradigm. Behav Neurosci 100: 11-22.

Jay TM. 2003. Dopamine: A potential substrate for synaptic plasticity and memory mechanisms. Prog Neurobiol 69: 375-390.

Jensen J, McIntosh AR, Crawley AP, Mikulis DJ, Remington G, Kapur S 2003. Direct activation of the ventral striatum in anticipation of aversive stimuli. Neuron 40: 1251-1257.

Jovanovic T, Norrholm SD, Blanding NQ, Davis M, Duncan E, Bradley B, Ressler KJ. 2010. Impaired fear inhibition is a biomarker of PTSD but not depression. Depress Anxiety 27: 244-251.

Kluchen T, Kagerer S, Schweckendiek J, Tabbert K, Vaitl D, Stark R. 2009. Contingency learning in human fear conditioning involves the ventral striatum. Hum Brain Mapp 30: 3636-3644.

Koch M, Schmid A, Schnitzler H. 1996. Pleasure-attenuation of startle is disrupted by lesions of the nucleus accumbens. NeuroReport 7: 1442-1446.

LaBar KS, Gatenby JC, Gore JC, LeDoux JE, Phelps EA. 1998. Human amygdala activation during conditioned fear acquisition and extinction: A mixed-trial fRMI study. Neuron 20: 937-945.

Laux L, Glanzmann P, Schaffner P, Spielberger CD. 1981. Das state-trait angstinventar. Beltz Test, Weinheim, Germany.

Lavond DG, Kim JJ. 1993. Mammalian brain substrates of aversive classical conditioning. Annu Rev Psychol 44: 317-342.

LeDoux JE. 2000. Emotion circuits in the brain. Annu Rev Neurosci 23: $155-184$.

LeDoux J. 2012. Rethinking the emotional brain. Neuron 73: 653-676.

Leknes S, Lee M, Berna C, Andersson J, Tracey I. 2011. Relief as a reward: Hedonic and neural responses to safety from pain. PLOS ONE 6: e17870. doi: 10.1371/journal.pone.0017870.

Levita L, Hare TA, Voss HU, Glover G, Ballon FDJ, Casey BJ. 2009. The bivalent side of the nucleus accumbens. NeuroImage 44: 1178-1187.

Li J, Schiller D, Schoenbaum G, Phelps EA, Daw ND. 2011. Differential roles of human striatum and amygdala in associative learning. Nat Neurosci 14: $1250-1252$.

Lissek S, Powers AS, McClure EB, Phelps EA, Woldehawariat G, Grillon C, Pine DS. 2005. Classical fear conditioning in the anxiety disorders: A meta-analysis. Behav Res Ther 43: 1391-1424.

Lohr JM, Olatunji BO, Sawchuk CN. 2007. A functional analysis of danger and safety signals in anxiety disorders. Clin Psychol Rev 27: 114-126.

Maren S. 2000. Long-term potentiation in the amygdala: A mechanism for emotional learning and memory. Trends Neurosci 23: 345-346.

Martin JH. 1991. Autoradiographic estimation of the extent of reversible inactivation produced by microinjection of lidocaine and muscimol in the rat. Neurosci Lett 127: 160-164.

Mechias ML, Etkin A, Kalisch R. 2010. A meta-analysis of instructed fear studies: Implications for conscious appraisal of threat. NeuroImage 49: 1760-1768.

Mineka S, Oehlberg K. 2008. The relevance of recent developments in classical conditioning to understanding the etiology and maintenance of anxiety disorders. Acta Psychol 127: 567-580.

Moscovitch A, LoLordo VM. 1968. Role of safety in the Pavlovian backward fear conditioning procedure. J Comp Physiol Psych 66: 673-678.

Muller J, Corodimas KP, Fridel Z, LeDoux JE. 1997. Functional inactivation of the lateral and basal nuclei of the amygdala by muscimol infusion prevents fear conditioning to an explicit conditioned stimulus and to contextual stimuli. Behav Neurosci 111: 683-691.

Murray EA. 2007. The amygdala, reward and emotion. Trends Cogn Sci 11: 489-497.

Paton JJ, Belova MA, Morrison SE, Salzman CD. 2006. The primate amygdala represents the positive and negative value of visual stimuli during learning. Nature 439: 865-870.

Pavlov IP. 1927. Conditioned reflexes: An investigation of the physiological activity of the cerebral cortex. Oxford University Press, London, UK.

Paxinos G, Watson C. 1997. The rat brain in stereotaxic coordinates. Accademic Press, San Diego, CA.

Phelps EA, LeDoux JE. 2005. Contributions of the amygdala to emotion processing: From animal models to human behavior. Neuron 48: $175-187$.

Phelps EA, Delgrado MR, Nearine KI, LeDoux JE. 2004. Extinction learning in humans: Role of the amygdala and vmPFC. Neuron 43: 897-905.

Reiff S, Katkin ES, Friedman R. 1999. Classical conditioning of the human blood pressure response. Int J Psychophysiol 34: 135-145.

Rescorla RA. 1988. Pavlovian conditioning. It's not what you think it is. Am Psychol 43: 151-160.

Robbins TW, Everitt BJ. 1996. Neurobehavioural mechanisms of reward and motivation. Curr Opin Neurobiol 6: 228-236.

Rogan MT, Staubli UV, LeDoux JE. 1997. Fear conditioning induces associative long-term potentiation in the amygdala. Nature 390: 604-607. 
Rogan MT, Leon KS, Perez DL, Kandel ER. 2005. Distinct neural signatures for safety and danger in the amygdala and striatum of the mouse. Neuron 46: 309-320.

Schiller D, Freeman JB, Mitchell JP, Uleman J, Phelps EA. 2009. A neural mechanism of first impressions. Nat Neurosci 12: 508-514.

Schmidt A, Koch M, Schnitzler HU. 1995. Conditioned pleasure attenuates the startle response in rats. Neurobiol Learn Mem 64: 1-3.

Schultz W, Dayan P, Montague PR. 1997. A neural substrate of prediction and reward. Science 275: 1593-1599.

Schwienbacher I, Schnitzler HU, Westbrook RF, Richardson R, Fendt M. 2006. Carbachol injections into the nucleus accumbens disrupt acquisition and expression of fear-potentiated startle and freezing in rats. Neuroscience 140: 769-778.

Seymour B, O'Doherty JP, Koltzenburg M, Wiech K, Frackowiak R, Friston K, Dolan R. 2005. Opponent appetitive-aversive neural processes underlie predictive learning of pain relief. Nature 8: 1234-1240.

Seymour B, Daw N, Dayan P, Singer T, Dolan R. 2007. Differential encoding of losses and gains in the human striatum. J Neurosci 27: 4826-4831.

Siebert M, Markowitsch HJ, Bartel P. 2003. Amygdala, affect and cognition: Evidence from 10 patients with Urbach-Wiethe disease. Brain 126: $2627-2637$.

Solomon RL. 1980. The opponent-process theory of acquired motivation. The cost of pleasure and the benefit of pain. Am Psychol 35: $691-712$.
Strack F, Deutsch R. 2004. Reflective and impulsive determinants of social behavior. Pers Soc Psychol Rev 8: 220-247.

Sutton RS, Barto AG. 1990. Time-derivative models of Pavlovian reinforcement. In Learning and computational neuroscience: Foundations of adaptive networks (ed. M Gabriel, J Moore), pp. 497-537. The MIT Press, Cambridge, MA.

Tabbert K, Stark R, Kirsch P, Vaitl D. 2006. Dissociation of neural responses and skin conductance reactions during fear conditioning with and without awareness of stimulus contingencies. NeuroImage 32: $761-770$.

Tanimoto H, Heisenberg M, Gerber B. 2004. Experimental psychology: event timing turns punishment to reward. Nature 430: 983 . doi: $10.1038 / 430983 a$.

Wagner AR. 1981. SOP: A model of automatic memory processing in animal behavior. In Information processing in animals: Memory mechanisms (ed. NE Spear, RR Miller), pp. 5-47. Erlbaum, Hillsdale, NJ.

Wang DV, Tsien JZ. 2011. Convergent processing of both positive and negative motivational signals by the VTA dopamine neuronal populations. PLOS ONE 6: e17047. doi: 10.1371/journal.pone.0017047.

Yarali A, Niewalda T, Chen Y, Tanimoto H, Duerrnagel S, Gerber B. 2008. Pain relief learning in fruit flies. Anim Behav 76: 1173-1185.

Received May 2, 2012; accepted in revised form July 29, 2012. 


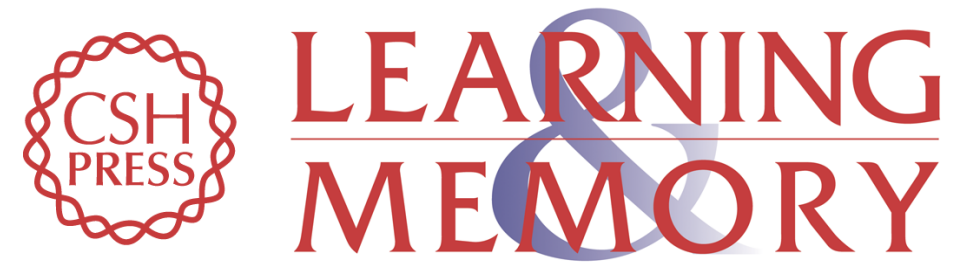

\section{Onset and offset of aversive events establish distinct memories requiring fear and reward networks}

Marta Andreatta, Markus Fendt, Andreas Mühlberger, et al.

Learn. Mem. 2012, 19:

Access the most recent version at doi:10.1101/Im.026864.112

Supplemental http://learnmem.cshlp.org/content/suppl/2012/10/16/19.11.518.DC1
Material

References This article cites 72 articles, 6 of which can be accessed free at: http://learnmem.cshlp.org/content/19/11/518.full.html\#ref-list-1

License Freely available online through the Learning \& Memory Open Access option.

Email Alerting Receive free email alerts when new articles cite this article - sign up in the box at the Service top right corner of the article or click here. 